\title{
Utilizing Steel Slag in the Removal of Suspended Solids from Dewatered Construction Water
}

\author{
Alaa Al Hawari \\ a.hawari@qu.edu.qa \\ Department of Civil and Architectural Engineering, Qatar University, Doha, Qatar \\ Abdelrahman Tariq \\ aa083874@qu.edu.qa \\ Department of Civil and Architectural Engineering, Qatar University, Doha, Qatar \\ Ahmed T. Yasir \\ ay1107095@qu.edu.qa \\ Department of Civil and Architectural Engineering, Qatar University, Doha, Qatar \\ Mohamed A. Ayari \\ arslana@qu.edu.qa \\ Center for Excellence in Teaching and Learning, Qatar University, Doha, Qatar
}

\begin{abstract}
Construction dewatering is an operation used to remove shallow groundwater that infiltrates construction sites. After recovering this water from the construction sites, the water is either discharged to the sea, injected in deep groundwater aquifers, or treated and reused in some other applications. However, municipal and industrial application of this water is unfeasible due to its poor quality. Thus, in this study, dewatered construction water is being treated utilizing waste steel slag in order to improve the quality of the water. The $\mathrm{pH}$ of the dewatered construction water used for this study was 7.59 and the average diameter of steel slag used was $425 \mathrm{~nm}$. For coagulation, the impact of the mass of steel slag and the contact time on the quality of dewatered construction water were studied. By using $5 \mathrm{gm} / \mathrm{L}$ of steel slag, more than $85 \%$ of the total suspended solids and turbidity were removed within 30 minutes.
\end{abstract}

Keywords: Coagulation; Steel slag; Dewatered construction water; Total suspended solids

\section{INTRODUCTION}

Deep excavation for construction purposes often results in water seepage from underground reservoirs, especially if the water table is high (Calin, 2017). This water might delay the construction process and damage the infrastructure around the construction site (Serag, 2008). The dewatering process of the construction sites can be done by pumping methods or exclusion methods (Somerville, 2008). Once dewatered, this construction water is generally discharged to the sea (Tchobanoglous, 2001). However, this dewatered construction water has low salinity, low concentration of heavy metals and low concentration of total suspended solid (Hawari, 2018). Thus, this water can be reclaimed by low cost treatment process.

Hawari et al. (2018) treated dewatered construction water using a settling tank and a multimedia sand filter (Hawari, 2018). The dewatered construction water had an initial turbidity of 350 NTU. After 1 hour of settling time, the turbidity reduced to 26 NTU. And 
by filtering the dewatered construction water using multimedia sand filter, the turbidity was reduced to 24 NTU (Hawari, 2018). Both technologies showed similar turbidity removal efficiency. The efficiency of the settling process can be improved by adding coagulants. Addition of coagulants would neutralize the surface charge of the colloids and improve coalescence in the water. This will help in forming large flocks of colloids which will settle faster. However, using commercial coagulants will reduce the cost effectiveness of the treatment process. Thus, in this paper the feasibility of using steel slag as a coagulant for the treatment of dewatering construction water was investigated.

Steel slag is a by-product of steel manufacturing industry. Limestone is used as a melting point reducing agent in order to remove the impurities in the iron ore which get deposited as steel slag (Dhoble, 2018). Steel slag is usually generated in large quantities and its disposal poses a significant burden on steel factories (Dhoble, 2018). This waste by-product possesses a porous structure with a high surface area and contains oxides such as $\mathrm{FeO}-\mathrm{Fe}_{2} \mathrm{O}_{3}-\mathrm{SiO}_{2}-\mathrm{CaO}-\mathrm{Al}_{2} \mathrm{O}_{3}$. These oxides show characteristics that are similar to coagulants. They have high adsorption capacity and have been used effectively in many studies to remove ammonia, nitrogen, phosphorous and metals from water through adsorption and precipitation (Shilton, 2006; Xiong, 2008; Yi, 2012; Liu, Yuan, 2011). Yin et al. removed $90 \%$ of COD from non-degradable organic wastewater using steel slag as a catalyst in an oxidative degradation process (Yin, 2016). Feng et al. used steel slag as an adsorbent to treat acid mine wastewater (Feng, 2004). Since, the density of steel slag is between 3.3 and $3.6 \mathrm{~g} / \mathrm{cm}^{3}$ it can be easily separated from water by gravity settling (Yi, 2012).

Thus, in this study, a coagulation process using steel slag as coagulant is being proposed for reclaiming the dewatered construction water. The effect of concentration of steel slag and the effect of residence time was studied.

\section{MATERIAL AND METHOD}

\subsection{Collection of water samples}

Dewatered construction water samples were collected from a construction site located at the Industrial Area, $13 \mathrm{~km}$ away from the center of Doha city. Table 1 shows the composition of the dewatering construction water and the method of determination.

Table 1: Properties of the collected dewatering construction water and the determination method

\begin{tabular}{llll}
\hline Parameter & Unit & Sample & Testing methods \\
& & & \\
\hline $\mathrm{pH}$ & & 7.59 & SMWW 4500 H+.B \\
Turbidity & NTU & 350 & SMWW 2130 B \\
Total Solids (TS) & ppm & 3,015 & SMWW 2540 B \\
Total Suspended Solid (TSS) & ppm & 91.2 & Hach Method 8006 \\
TDS (Calculated: TS -TSS) & ppm & 2,924 & SMWW 2540 \\
\hline
\end{tabular}




\subsection{Steel slag}

The steel slag used in this study was provided by Qatar Steel. The composition of steel slag was analyzed using EDAX. The EDAX analysis in Figure 1 shows that $40 \%$ of the total weight of steel slag is made up of iron oxides and calcium oxides. In addition, other metals such as Magnesium (Mg) and Aluminum (Al) are present in small quantities. The steel slag particles have gravel like texture and a blackish color. Moreover, white dust particles are found within the steel slag. In order to remove the dust particles, the slag particles were washed with distilled water. Subsequently, the slag particles were grinded using a Planetary Ball Mill (PM $100 \mathrm{~cm}$, Retsch) for 5 minutes at 500 RMP and then passed through 40-micron filter. Thus, collecting steel slag particles with an average size of $425 \mu \mathrm{m}$. The grinded steel slag can be seen in Figure 2.

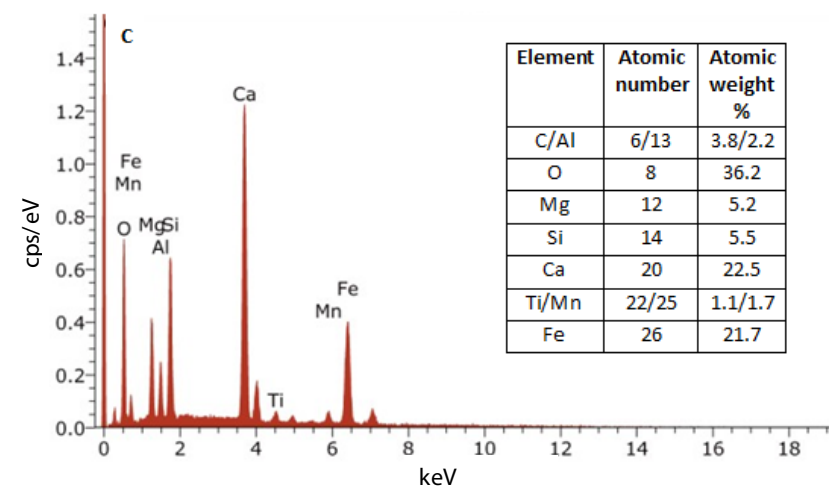

Figure 1: EDAX analysis of the slag sample prior to EC

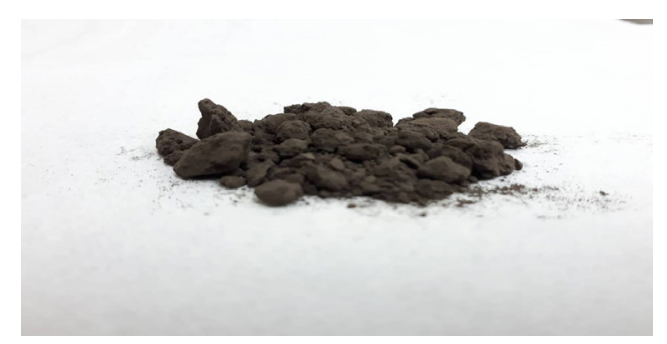

Figure 2: Grinded steel slag sample

\subsection{Experimental setup}

After collecting the dewatered construction water and characterizing them, the removal of suspended solids was done to improve the turbidity of the water. It was done using jar test apparatus (PHIPPS \& BIRD STIRRER 7790-402). The jar test apparatus can accommodate up to 6 beakers at the same time. $600 \mathrm{ml}$ of water sample was added to each beaker in the beginning, this volume is enough to ensure that the stirrers is submerged in the water. After adding the steel slag, the sample was stirred for a fixed amount of time. During this process, the $\mathrm{pH}$ of the solution was maintained at 12 . After mixing, the samples were allowed to stay still for few minutes for the suspended particles to settle down. After the coagulation process, the turbidity and total suspended solid concentration of the water was measured. The mass of steel slag and the contact time was optimized by repeating the experiment with varying the mass of steel slag 
and contact time. After optimizing the process, the coagulation process was repeated with commercial chemical coagulants and its performance was compared with the performance of the proposed coagulant (steel slag).

After the experiment the total suspended solids removal and turbidity removal were calculated as (Hafiz, 2019):

$$
\text { TSS Removal } \%=\frac{\text { Original Sample TSS }- \text { Treated Sample TSS }}{\text { Original Sample TSS }} \times 100 \%
$$

$$
\text { Turbidity Removal } \%=\frac{\text { Original Sample Turbidity }- \text { Treated Sample Turbidity }}{\text { Raw Sample Turbidity }} \times 100 \%
$$

\section{RESULTS AND DISCUSSION}

\subsection{Effect of steel slag concentration}

The effect of steel slag concentration on the removal efficiency of total suspended solids (TSS) and turbidity was investigated. The $\mathrm{pH}$ of the dewatered construction water was 7.59. The used steel slag particles had a diameter of $425 \mathrm{~nm}$. The test was run for 60 minutes and the TSS removal and turbidity removal were calculated after 60 minutes. The concentration of steel slag used was 5, 10, 15, 20 and $50 \mathrm{mg} / \mathrm{L}$. As seen in Figure 3, when the concentration of steel slag was $5 \mathrm{~g} / \mathrm{L}$, the suspended solids removal rate was almost $97 \%$. As the concentration of steel slag increased, the removal rate of suspended solids remained constant. When the concentration of steel slag was $50 \mathrm{mg} / \mathrm{L}$, the removal rate of suspended solids decreased to reach $93.8 \%$. Initially, the removal efficiency of suspended solid was high due to reduction of zeta potential of the water. Reduction of zeta potential reduced the surface charge of the colloids and made Van der Walls's force more dominant in the water. This caused faster agglomeration of colloids and increased TSS removal efficeincy was observed (Shilton, 2006; Xiong, 2008; Yi, 2012; Liu, 2011). Using $5 \mathrm{~g} / \mathrm{L}$ of steel slag resulted in turbidity removal rate of $97 \%$. The turbidity removal rate did not improve by increasing concentration of the steel slag. On the contrary, increasing the steel slag concentration to $50 \mathrm{gm} / \mathrm{L}$ decresed the turbidity removal efficiency to $91.21 \%$. This is because addition of excess steel slag increases the turbidity of the water.

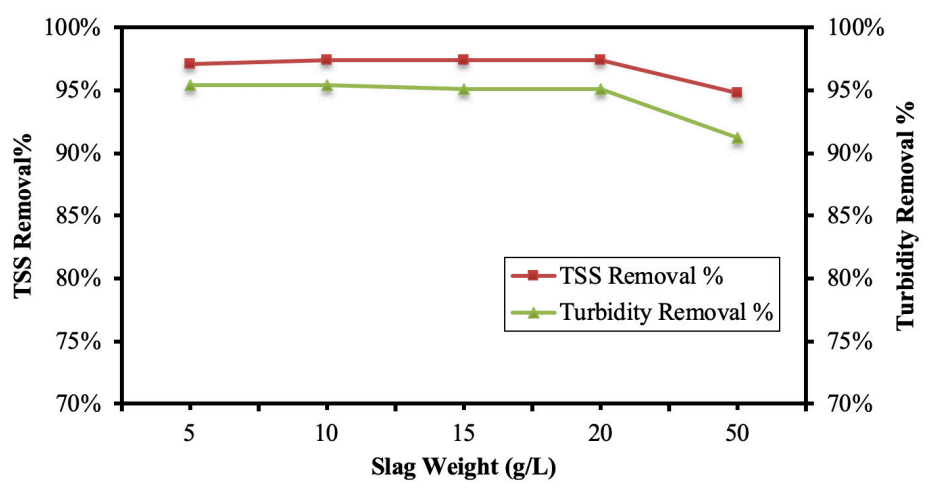

Figure 3: Different weights (g) of $425 \mathrm{~nm}$ steel slag turbidity and TSS removal \% values 


\subsection{Effect of contact time}

The impact of contact time on total suspended solid (TSS) and turbidity removal rate was also investigated. The concentration of the steel slag was kept constant at $5 \mathrm{~g} / \mathrm{L}$. The TSS and turbidity removal rates were calculated after 5 minutes, 15 minutes, 30 minutes and 60 minutes of coagulation. Figure 4 shows the TSS and turbidity removal rate at different contact times. It can be seen, that after 5 minutes of contact time, the suspended solids removal rate was almost $60 \%$. As the contact time increased, the removal rate of suspended solids also increased. As the contact time approached 60 minutes, the removal percentage of suspended solids reached about $91.6 \%$. Similar trend can be seen for the turbidity removal rate. After 5 minutes of coagulation, the turbidity removal was $6.1 \%$. The turbidity removal increased and reached $89.6 \%$ after 60 minutes of operation. It can be noticed that after 30 minutes of contact time, the TSS and turbidity removal rates do not improve significantly. This is mainly because, all the steel slag added has been used already and to improve TSS and turbidity removal rate, the concentration of steel slag in the water has to be increased.

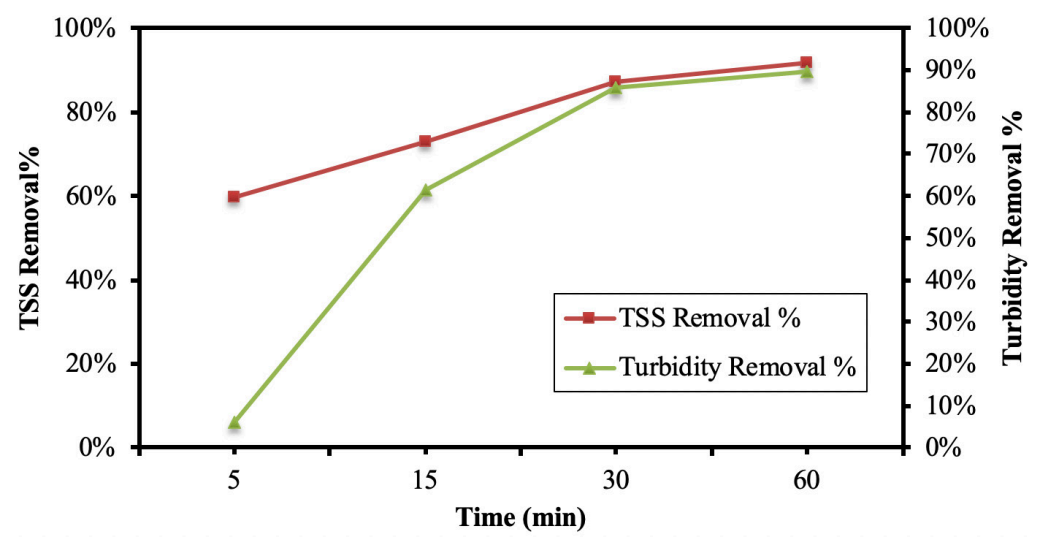

Figure 4: Turbidity and TSS removal \% over time range ( $\mathrm{min}$ ) of $425 \mathrm{~nm}$ steel slag

\section{CONCLUSION}

In this study, a coagulation process has been proposed that utilizes steel slag as coagulant for treatment of dewatered construction water. The effect of concentration of the steel slag and contact time for the process on total suspended solid and turbidity removal rates have been studied. The $\mathrm{pH}$ of the dewatered construction water was 7.59 and the average radius of steel slag used for this study was $425 \mathrm{~nm}$. The study showed that, by adding $5 \mathrm{gm} / \mathrm{L}$ of steel slag, $85 \%$ of TSS and turbidity can be removed within 30 minutes. In future, the size of steel slag particle and $\mathrm{pH}$ of the water would be studied to improve the performance of the coagulation process. Moreover, the performance of steel slag as coagulant would be compared with commercially available coagulants.

\section{ACKNOWLEDGMENT}

The authors would like to thank Qatar University for the financial support. In addition, the authors would like to thank Qatar Steel for the supply of the steel slag samples. 


\section{REFERENCES}

Calin, N., Radu, C. \& Bica, I. (2017). Dewatering system of a deep of excavation in urban area - Bucharest case study. Procedia Engineering, 209, 210-215. DOI: https://doi.org/10.1016/j. proeng.2017.11.149.

Dhoble, Y. N. \& Ahmed, S. (2018). Review on the innovative uses of steel slag for waste minimization. Journal of Material Cycles and Waste Management, 20(3), 1373-1382. DOI: 10.1007/ s10163-018-0711-z.

Feng, D., van Deventer, J. S. J. \& Aldrich, C. (2004). Removal of pollutants from acid mine wastewater using metallurgical by-product slags. Separation and Purification Technology, 40(1), 61-67. DOI: https://doi.org/10.1016/j.seppur.2004.01.003.

Hafiz, M. A., Hawari, A. H. \& Altaee, A. (2019). A hybrid forward osmosis/reverse osmosis process for the supply of fertilizing solution from treated wastewater. Journal of Water Process Engineering, 32, 100975. DOI: https://doi.org/10.1016/j.jwpe.2019.100975.

Hawari, A. H., Al-Qahoumi, A., Ltaief, A., Zaidi, S. \& Altaee, A. (2018). Dilution of seawater using dewatered construction water in a hybrid forward osmosis system. Journal of Cleaner Production, 195, 365-373. DOI: https://doi.org/10.1016/j.jclepro.2018.05.211.

Serag, E., Oloufa, A. \& Malone, L. (2008). Reconciliation of owner and contractor views in heavy construction projects. Journal of Professional Issues in Engineering Education and Practice, 134(1), 128-137. DOI:10.1061/(ASCE)1052-3928(2008)134:1(128).

Shilton, A. N., Elmetri, I., Drizo, A., Pratt, S., Haverkamp, R. G., \& Bilby, S. C. (2006). Phosphorus removal by an 'active' slag filter-a decade of full scale experience. Water Research, 40(1), 113-118.DOI:https://doi.org/10.1016/j.watres.2005.11.002.

Somerville, S. H. (2008). Control of Groundwater for Temporary Works. Retrieved from Construction Industry Research and Information Association (CIRIA).

Tchobanoglous, G., Burton, F. L. \& Stensel, H. D. Wastewater Engineering: An Overview. In Wastewater Engineering, Treatment and Reuse (Fourth Edition ed.): Metcalf \& Eddy, Inc.

Xiong, J., He, Z., Mahmood, Q., Liu, D., Yang, X. \& Islam, E. (2008). Phosphate removal from solution using steel slag through magnetic separation. Journal of Hazardous Materials, 152(1), 211-215. DOI: https://doi.org/10.1016/j.jhazmat.2007.06.103.

Yi, H., Xu, G., Cheng, H., Wang, J., Wan, Y., \& Chen, H. (2012). An Overview of Utilization of Steel Slag. Procedia Environmental Sciences, 16, 791-801. DOI: https://doi.org/10.1016/j. proenv.2012.10.108

Yin, S., Gao, B. \& Chen, X. (2016). Treatment of non-degradable organic wastewater with steel slag catalyst (Vol. 10).

Yu Liu, S., Yuan Xu, Y., Gao, J., Wei Lu, C. \& Jin Yang, Y. (2011). Preparation and Characterization of Steel Slag Adsorbent (Vol. 48-49).

Cite this article as: Al Hawari A., Tariq A., Yasir A. T., Ayari M. A., "Utilizing Steel Slag in the Removal of Suspended Solids from Dewatered Construction Water", International Conference on Civil Infrastructure and Construction (CIC 2020), Doha, Qatar, 2-5 February 2020, DOI: https://doi. $\operatorname{org} / 10.29117 /$ cic. 2020.0095 